\title{
EXPLORING GENERIC STRUCTURE POTENTIAL OF SELECTED EDITORIALS IN THE MYANMAR TIMES NEWSPAPER
}

\author{
Ae Mon Kyaw ${ }^{1}$, Xin Zhiying ${ }^{2}$ \\ 1,2Xiamen University, Xiamen, China \\ E-mail: kyawaemon@gmail.com
}

Received: 12 November 2019

Accepted: 04 December 2019

\begin{abstract}
Systemic Functional Linguists introduced Generic Structural Potential (GSP) that can be used to distinguish different social activities of a text. A variety of researches have been conducted on Generic Structural Potential of the editorials of other countries. However, no research has been conducted on the editorials of Myanmar newspaper. Therefore, The Myanmar Times newspaper, written in English, is chosen to carry out this research. The aim of the research paper is to identify the schematic structural elements of the editorials in The Myanmar Times newspaper. The materials are measured using Generic Structure Potential proposed by Halliday and Hason (1985). The result of the study shows that there are two obligatory elements and five optional elements. Heading $(\mathrm{H})$, and Contributing the Writer's Opinion $(O)$ are obligatory while Picture (P), Caption(C), Addressing the issue (AI), Background Information (BI), and Discussing the issue Raised (D) are optional elements. The sequence of the elements follows the procedure $\mathrm{H}^{\wedge}$ $(\mathrm{P})^{\wedge}\{*(\mathrm{BI}) *(\mathrm{AI}) *(\mathrm{D})\}^{\wedge} \mathrm{O}$.
\end{abstract}

Keywords: Systemic Functional Linguistics, The Myanmar Times News, Generic Structure Potential, editorials

\section{Introduction}

According to Eggins (2004, p. 58), “... as situations, or contexts, recur, so we develop recurrent ways of using language.". Language realizes the recurrence of the contexts or register, which in turn realizes the genre. Everyone acquires knowledge about the Genre of a specific text where their culture belongs before they knew themselves. Genre Analysis is "bringing this unconscious cultural knowledge to consciousness" (Eggins, 2004, p. 84).

The study of Generic Structure Potential has been conducted in many fields; football matches, advertising, talk show, folktales, feature articles, editorials, etc. The findings of the study are suggested for teaching in class and training the career-oriented courses. Every text has genre and every genre has its own potential. If a text can't be categorized as a specific genre, this is not a text. Eggins (2004, p. 55) stated that "if a text can't easily be attributed to a genre, then it is in some ways a problematic text". However, the genre of a text can vary from another one with same function depending on the culture, individual personalities.

Genre analysis can help us to understand the culture of the society. The analysis of genre functions in four different ways. First, it can be used to distinguish between successful, appropriate texts and those that are not. Second, it is used to "explore the ways genres from different contexts are similar to and different from each other" (Eggins, 2004, p. 74). Third, it can reflect the culture and the critical reader of the text can exploit the culture from the analysis of the genre (Eggins, 2004). 
Editorials are worth researching as it conveys the writer's subjective opinion unlike the objective reports in newspaper. Editorial is a kind of persuasive text. It is interesting how the editors construct the text. The detailed study of the editorials can help the learners of English language with the structure of opinion essays. Secondly, it would be a great resource that can reflect the culture of the writer through his own perceptions, voice, and making choices.

The present study will also look at the 25 editorials from The Myanmar Times newspaper and produce the Generic Structure Potential of the editorials. This study will identify the schematic structure of the selected texts.

\section{Literature Review}

\subsection{What is Generic Structure Potential?}

Martin (1984, p.25) defined Genre as "a staged, goal-oriented, purposeful activity in which speakers engage as members of our culture" and "Less technically, Genres are how things get done, when language is used to accomplish them" ( Martin, 1985, p. 248). Halliday and Hasan (1985) defined Genre as a meaning which results from language which does a particular job in a particular contextual configuration. The generic identity of a text builds up on three dimensions: register configuration, schematic structure and realizational patterns. Register configuration is the institutalization of the repeated patterns or habits within the recurrent register variables, which leads to genre. Genre is composed of various schematic structures, or step by step, goal-oriented stages, which in turn can be analyzed, realized by the linguistic structures.

Halliday and Hasan (1985) introduced the term Contextual Configuration (CC). Contextual Configuration (CC) means the combination of field, tenor and mode. Whenever a social activity occurs, the context variables always go together with it. For example, an act of a sale assistant selling an item embodies what the social function is about (field), who she is talking to (tenor) and how she is communicating with (mode). As contextual configuration (CC) exists where the social activity occurs, it is regarded that the structure of the text can be predicted and measured using the Contextual Configuration. The text structure that Contextual Configuration can predict is as follows;

1. Obligatory elements

2. Optional elements

3. Sequencing of elements

4. Recursiveness
- What elements must occur?

- What elements may occur?

- Where must and can the elements occur?

- How often can the elements occur?

In other words, the exploration of the obligatory elements can decide the genre of the text. On the other way round, the study of the structural elements can decide the obligatory elements, and optional elements. Obligatory elements can identify the missing elements in the particular text and differentiate the different text types, and the optional elements can tell the variety of the structure potential of the genre, differentiate the writers' language choices "to achieve private intentions within the framework of socially recognized purposes" (Bhatia, 2013, p. 49). In other words, the obligatory elements determine the actual generic structure of a particular text and the optional elements lead to the generic structural potential of a genre. Halliday and Hasan (1985) analyze the genre of a shop transaction to explore the obligatory and optional elements. The model will be elaborated in the data coding section.

\subsection{Editorials}

An editorial, a distinctive sub-genre of newspaper, is a branch of "Opinion" section in The Myanmar Times newspaper and covers one page. An editorial provides the editors' opinion 
concerning the current news. An editorial is defined as "an article in a newspaper that gives the opinion of the editor or publisher on a topic or item of news" (Sinclair, 1995, p.93, as cited in Fartousi \& Dumanig, 2012, p. 373). Spencer (1924, as cited in Xin, 2012, p. 18) also stated that "An editorial may be defined as a presentation of fact and opinion in concise, logical, pleasing order for the sake of entertaining, of influencing opinion, or of interpreting significant news in such a way that its importance to the average reader will be clear". With the presentation of the editor's opinion, an editorial is the bridge for the readers to provoke the critical thinking or influences the readers' thought in some way. There have been a number of studies on the section of newspaper editorials.

\subsection{Previous Researches about Generic Structure Potential}

Sunday \& Fagunleka (2017) examined the "Generic Structure Potential of Feature Articles in Nigerian Newspaper". The method of the research used is Halliday and Hason's GSP model (1985) and the result showed three obligatory elements: Headline, Orientation and Addressing the Issue; and three optional elements: Feature Lead, Proffering a Solution and Moral Lesson. In addition, the sequence of the elements is also researched.

Olagunju (2015) conducted a research on "Generic Structure Potential of Football Matches in Newspaper Reporting". Using the theory of Halliday and Hason (1985), the research found out that Nigeria news report consists of four obligatory elements: Title [T], Preamble [P], Online Thesis [OT], and Online Thesis Expatiation [OTE] and six optional elements: Voice Insertion, Offline Thesis Insertion and Offline Thesis Expatiation, Evaluation, Prediction and Winding Up.

Ansary \& Babaii (2005) did a research on "Generic Integrity of Newspaper Editorials: A Systemic Functional Perspective". They studied 30 English newspaper editorials from The Washington Times and discovered that the structural elements of editorials include four obligatory elements (Run-on Headline, Addressing an Issue, Argumentation, and Articulating a Position); and some optional elements (providing Background Information, and Initiation of Argumentation. The schematic structure of editorials found in English newspaper is $\mathrm{RH}^{\wedge}[(\mathrm{BI}) . \mathrm{Al}]^{\wedge}\left\{(\mathrm{IA})^{\wedge} \mathrm{A} 1^{\wedge} \mathrm{A} 2^{\wedge} \mathrm{A} A . .{ }^{\wedge}(\mathrm{CA})\right\}^{n} \wedge\left\{\mathrm{AP} 1^{\wedge} \mathrm{AP} 2^{\wedge} \mathrm{AP} . ..\right\} \mathrm{m}$.

Ansary \& Babaii (2009) compared the generic structural potential of three English newspaper editorials in order to explore the variation based on different cultures within the same genre. Analyzing 30 editorials each from The Washington Times, The Iran News and The Pakistan Today, the researcher found out no significant difference in the use of rhetorical elements. Therefore, the result shows that the unmarked elements of the editorials are the same as the findings of the research conducted in 2005. There is no cultural effect on the generic structure of the newspaper editorials.

There have been some researches about Generic Structure Potential of Newspaper editorials in different cultures. However, very few researches have been done for Myanmar Newspaper editorials. Martin and Rothery $(1986$, p. 243) stated that "Genre refers to the staged purposeful social process through which a culture is realized in a language". This means that different cultures follow different generic patterns and can be realized through genres. The Myanmar Times editorial in Myanmar context, in this paper, is selected to discover how it is different from the editorials in the different cultures.

\section{Research Questions}

(1) What are the schematic structure elements of the editorials in The Myanmar Times newspaper? 
Exploring Generic Structure Potential of Selected Editorials in the Myanmar Times Newspaper, Ae Mon Kyaw, Xin Zhiying

(2) How often do the schematic structural elements occur in The Myanmar Times newspaper editorials?

(3) What is the sequence of the schematic structural elements in The Myanmar Times newspaper editorials?

\section{Data Coding}

In this research, thirty articles were collected from The Myanmar Times newspaper. The articles are intentionally selected from May 2018 to December 2018 to avoid diachronically variation.

Selected materials are analyzed using Halliday and Hason's contextual configuration (1985). Structural elements of the editorials are identified based on the meaning. As in the related studies, the boundary between the structural elements is made with the help of the linguistic elements in the text and typographical clues. Linguistic elements include discourse markers such as "First", "Second", "Third", "As a result", "However", etc. Typological clues include order of presentation, paragraph divisions, italics and underlining.

Halliday and Hasan's (1985) generic structural potential to the grocery shopping is the model for the present research data coding. The dialogue between the sale assistant and the customer is analyzed in order to identify the obligatory elements and optional elements.

\section{Sale Request}

Customer : Can I have ten oranges and a kilo of bananas please?

Sale Compliance

Sales Assistant : Yes, anything else?

Customer : No thanks.

Sale

Sales Assistant : That'll be dollar forty.

Purchase

Customer : Two dollars

Purchase Closure

Sales Assistant : Sixty, eighty, two dollars. Thank you.

Eggins (2004, p. 64) identified the obligatory elements as follows; " To discover which elements of the schematic structure are the defining or obligatory elements, we can ask; what stages could we leave out and yet still have a transactional text?". In the aforementioned dialogue, the Sale Request "Can I have ten oranges and a kilo of bananas please?" is recurrent, typical and betrays what type of transaction it is and is the very first obligatory element in the dialogue. Likewise, the stages of Sale Compliance, Sale, Purchase and Purchase Closure also define the text type and are regarded as obligatory elements. This dialogue can be added optional elements to have the extended variation. For example, Sale Initiation can be added before the Sale Request as follows;

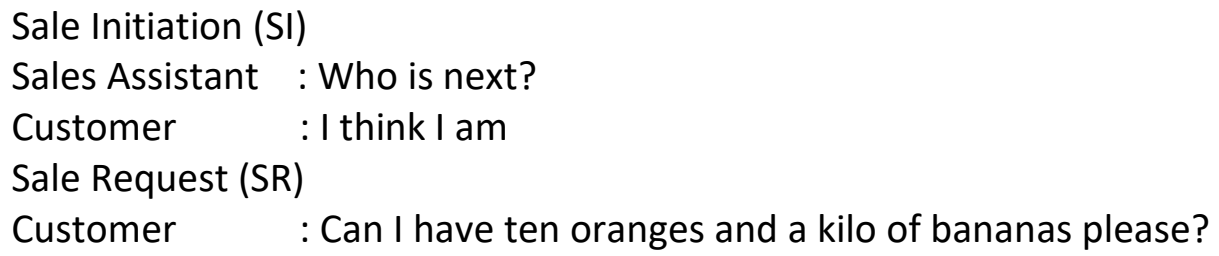

In this case, the clause "Who is next?" could be heard in the classroom asking for the volunteers to present the ideas. Thus, this cannot identify the shopping genre and functions as the optional element. Halliday and Hassan (1985) describe the shopping genre as [(G). (SI) $\wedge$ ] [(SE.) $\left.\left.\left\{S R^{\wedge} S C^{\wedge}\right\}^{\wedge} S^{\wedge}\right\} P^{\wedge} P C(F)\right]$ 
The structural elements are interpreted as follows; Greeting (G), Sale Initiation (SI), Sale Enquiry (SE), Sale Request (SR), Sale Compliance (SC), Sale (S), Purchase (P), Purchase Closure $(P C)$, and Finis $(F)$. The meaning of the symbols is interpreted in this way ()$=$ the optionality of the enclosed elements. e.g G, SI, SE, and F. This means that SR, SC, S, P and PC are obligatory. The dot . = "more than one option" in sequence. [ ] = restraint on sequence. ${ }^{\wedge}=$ the number of the repetition of elements. That is to say, if SR occurs twice, then SC must also occur twice. Using this model, the present study analyses the structural elements of the editorials of The Myanmar Times Newspaper. The present study aims to identify the obligatory elements and optional elements of the selected editorials, the sequence of the elements.

\section{Findings}

\subsection{Obligatory elements and optional elements of the selected editorials}

This section explores the schematic structure stages of the editorials in The Myanmar Times newspaper using Halliday and Hason's (1985) contextual configuration (CC). In the research, it is found out that there are two obligatory elements; Headline, and Contributing the Writer's Opinion while there are five optional elements: Photo, Caption, Background Information, Addressing the Issue and Discussing the theme or issue Raised.

\subsection{Headline $(\mathrm{H})$}

This element is always written in bold on the top of the article with bigger font than the follow-up content. It can attract the readers" attention. In other words, it can screen the readers. Taking a glance at the headline can give the general idea about the whole content. Some of the examples are given below;

- "Myanmar should not retreat into isolation" (The Myanmar Times editorial, 2018. September.14)

- "Exchange rate fever" (The Myanmar Times editorial, 2018. August.17)

\subsection{Photo (P) and Caption(C)}

Photos and captions are also an element of Newspaper editorials. One surprising thing to be discovered is that not all photos have a caption.

\subsection{Contributing the writer's opinion (0)}

The element 'Contributing the writer's opinion to the Theme or Issue' provides the writer's opinion, prediction, comment, or suggestions. It conveys the editor's voice and gives the readers thought-provoking questions. Some examples are given below.

"We have no idea. Here's what we do know: There are thousands of people in North Korea who will learn of Trump's latest statement. Thousands of people who had looked to America and its democratic allies to stand for their dignity and freedom as human beings will feel a bit less hopeful about their future. They will feel betrayed. They will be right to feel that way."

(The Myanmar Times editorial, 2018, June 15)

"The best solution lies within society itself, where the perspectives and attitudes of all people - men and women - have to change." (The Myanmar Times editorial, 2018, July 13) 
Exploring Generic Structure Potential of Selected Editorials in the Myanmar Times Newspaper, Ae Mon Kyaw, Xin Zhiying

\subsection{Background Information (BI)}

The element "Background Information" introduces the reader to the main theme of the article. It also signals the readers the content they are going to read and the organization of the passage. It positions at the beginning of the editorials. It can be found in all of the editorials. Thus, "Background Information" is the obligatory element. In addition, the types of Background Information are explored further based on Literary Devices Editors (2013) in order to find out the obligatory and optional elements. According to Literary Devices Editors. (2013), there are six types of Background Information. They are (1) Description Type, (2) Process Type, (3) Definition Type (4) Persuasive Type (5) Argumentative Type (6) Classification or Division Type. In this research, Argumentative Type, only one Definition Type and one Description Type are found to deliver the Background Information. However, it is interesting to note that the past events are frequently reported as the Background Information to explain the current situation.

\subsubsection{Argumentative Type of Giving the Background Information}

Argumentative type of background information occurs when the topic is introduced to the readers proposing the argument. This element occurs in 21 editorials out of 30 . This is an optional element with $70 \%$. Some paragraphs are provided as an example;

"In the past year, Myanmar rejected joint venture proposals involving Japan's ANA and Malaysia's Air Asia, citing the need to insulate (protect) local players from foreign competition."

(The Myanmar Times editorial, 2018, July 27)

\subsubsection{Definition Type of Giving the Background Information}

According to Literary Devices Editors 2013, definition type of background information is occurs "when readers become aware of the definition of the topic, as well as how it differs from other such similar terms and words."

"Nowadays, everybody who is somebody talks about tariffs. The word comes from somebody in the United States, somebody in China or somebody in Europe. The word simply implies some sort of customs duty imposed on imports. However, when politicians start using it as an intimidating weapon or tool of vengeance, it gets complicated and, well, homely."

(The Myanmar Times editorial, 2018, June 29)

\subsection{Addressing the Issue (AI)}

This element exists in most of the selected editorials. The editorials are usually concerned with politics; some are about environment and business. The issues to discuss are directly addressed at the beginning of the editorials.

“......, Myanmar has literally entered the digital age. A decade or so ago, having a mobile phone, no matter how big or thick it was, was a status symbol, even in Yangon and Mandalay. Well, very few people had been to Nay Pyi Taw in those bad old days, because the new capital was actually very new among most Myanmar people....." (The Myanmar Times editorial, 2018. June. 1)

“US President Donald Trump's meeting with North Korean leader Kim Jong Un"s special envoy Friday has raised the possibility of formally ending the 
Korean War. It was the first time Trump has mentioned such a possibility." (The Myanmar Times editorial, 2018. June. 5)

\title{
5.6 Discussing the Theme or Issue Raised (D)
}

The element discusses the themes or the issues introduced in the previous paragraphs. It is elaborated by giving reasons, consequences, solutions and the comments. The element "Discussing the Theme Raised" occupies the largest space of the editorial. The following are the examples for developing the issue using reasons, consequences and solutions, all of which are extracted from selected newspaper editorials.

"Then, there is the other big question. Why do we keep on fighting each other, or rather one another, after all these years - almost seven decades? Hatred and animosity may not be the answers. Territorial gain may be or may not be the answer. Or is it the resource curse? Isn't there any possibility the natural resources can be equally or justly shared? (The Myanmar Times editorial, 2018. May 11)

\begin{abstract}
"Active TB can weaken the brain, kidneys or spine, but it mainly attacks the lungs, causing coughing, fever and chills. Sufferers enable the bacteria's spread by expelling germ-containing droplets ...." "TB can be cured with a six-month regimen of four so-called first-line medicines: isoniazid, rifampicin, ethambutol and pyrazinamide. The cocktail helps kill bacteria that are resistant to any one of the drugs." (The Myanmar Times editorial, 2018, May 29)
\end{abstract}

\subsection{The Frequency of Structural Elements}

The occurrence of structural elements of Newspaper editorials can decide the obligatory and optional elements according to Halliday and Hason's (1985) Contextual Configuration (CC).

The frequency of the structural elements found in the editorials of The Myanmar Times newspaper is shown as below;

Table 1: Distribution of the structural elements of selected editorials in The Myanmar Times newspaper

\begin{tabular}{|c|c|c|}
\hline Name of the Elements & Frequency & Percentage \\
\hline Heading & 25 & $100 \%$ \\
\hline Picture & 9 & $36 \%$ \\
\hline Caption & 7 & $28 \%$ \\
\hline Background Information & 16 & $64 \%$ \\
\hline Addressing the Issue & 21 & $84 \%$ \\
\hline Discussing the theme or Issue Raised & 19 & $76 \%$ \\
\hline Writer's opinion & 25 & $100 \%$ \\
\hline
\end{tabular}

According to this table, it can be seen that two obligatory elements and five optional elements are found in the research. Headline $(\mathrm{H})$ and Writer's Opinion $(\mathrm{O})$ occur in all of the analyzed articles with $100 \%$ and are the obligatory elements. On the other hand, Picture (36\%), Caption (28\%), Background Information (64\%), Addressing the Issue (84\%) and Discussing the Issue Raised (76\%) are found in some of the articles. Therefore, it can be noted that Photo(P), Caption (C), Background Information (BI), Addressing the Issue (AI) and Discussing the Theme or Issue Raised (D), are optional elements. 
Exploring Generic Structure Potential of Selected Editorials in the Myanmar Times Newspaper, Ae Mon Kyaw, Xin Zhiying

\subsection{The sequence of the generic structure elements in The Myanmar Times newspaper}

In the previous section, we have explored the generic structure elements of the selected editorials from The Myanmar Times newspaper. They are Headline $(H)$ and Writer's Opinion (0), Picture (36\%), Caption (28\%), Background Information (64\%), Addressing the Issue (84\%) and Discussing the Issue Raised (76\%) In this section, the sequence of these elements is to be examined in the following way;

$\mathrm{H}^{\wedge}(\mathrm{P})^{\wedge}(\mathrm{C})\{*(\mathrm{BI}) *(\mathrm{Al}) *(\mathrm{D})\}^{\wedge} \mathrm{O}$

The caret $(\wedge)$ represents the fixed order of the stage; $H$ precedes $P$. The bracket ( ) decodes the optional stage of the elements. * is used to express the unordered stage of the elements, which means Background Information (BI), Addressing the Issue (Al) and Discussing the issue or theme Raised (D) do not have the fixed place. The use of ( ) shows the optional element. In other words, Picture, Caption, Background Information, Addressing the Issue, Discussing the issue or theme Raised are optional. Next, $\left\{{ }^{*}(\mathrm{BI}){ }^{*}(\mathrm{AI}){ }^{*}(\mathrm{D})\right\}^{\wedge} \mathrm{O}$ indicates that writer's opinion always follows the elements in the \{\} .

\section{Discussion}

In this research paper, 25 editorials - dating May 2018 to October 2018 - of The Myanmar Times newspaper are selected to discover the genre in Myanmar newspaper. The data is collected based on the Generic Structural Potential introduced by Halliday and Hasan (1985). The result of the research shows that there are two obligatory elements, namely Headline $(\mathrm{H})$ and Contributing the Writer's Opinion (O). They occur in all of the editorials of The Myanmar Times newspaper. Picture (36\%), Caption (28\%), Background Information (64\%), Addressing the Issue (84\%) and Discussing the Issue Raised (76\%) are found in some of the articles and are optional elements. The result is different from Sunday \& Fagunleka's (2017), and Ansary \& Babaii's (2005, 2009) and Pulido's (2011) finding. In their article, Addressing the Issue is the obligatory element. It is found out in The Myanmar Times newspaper that Addressing the Issue (84\%) is optional. Some of the editorials in The Myanmar Times newspaper are not addressed to the problem but give the background information about the current topic. For example, the editorial of "Panglong conferences, Panglong promises" share the background knowledge of the Panglong conferences; the location, the history, the representing committees of Panglong conferences; and the editor's opinion, especially prediction about coming Panglong conferences. Therefore, it is found out in this research that not all the selected editorials are addressed to the issue and argumentative.

Discussing the Theme or Issue Raised, an optional element, is $76 \%$. After addressing the issue, the issue raised is discussed providing solutions, factual results or factual causes of the issue or event in The Myanmar Times. At the end of the editorials is the editors' prediction about the particular but not Articulating a Position as in English newspaper editorials (see Ansary \& Babaii, 2005, 2009). Rather, it provides more factual information about the topic. This reflects the need to develop the culture of argumentation more in The Myanmar Times editorials.

Furthermore, it is noted that the schematic structural elements of The Myanmar Times editorials are sequenced in the following way: $\mathrm{H}^{\wedge}(\mathrm{P})^{\wedge}(\mathrm{C})\left\{{ }^{*}(\mathrm{BI}){ }^{*}(\mathrm{AI}){ }^{*}(\mathrm{D})\right\}^{\wedge} \mathrm{O}$. Heading and Writer's Opinion are both the obligatory elements while the other elements _ Photo, Caption, Background Information, Addressing the Issue and Discussing the Issue Raised-are optional. Heading always precedes Photo, which in turns precedes Caption. The elements within \{\} do not have the fixed position and each of them can occur any of the places within it, and Writer's Opinion (O) always follows the elements between \{\} . 


\section{Conclusion}

The paper studies the generic structure potential of the editorials of The Myanmar Times newspaper. Thirty editorials published in 2018 (May to October) are selected to analyze and the result shows four obligatory and two optional elements. The two obligatory elements are Heading $(\mathrm{H})$, and Contributing the Writer's Opinion (O). The four optional elements are Photo $(\mathrm{P})$ and Caption (C), Background Information (BI), Addressing the Issue (AI) and Discussing the Issue Raised (D). The sequence of the structural elements is $\mathrm{H}^{\wedge}(\mathrm{P})^{\wedge}(C)\left\{{ }^{*}(\mathrm{BI}){ }^{*}(\mathrm{Al}){ }^{*}(D)\right\}^{\wedge} \mathrm{O}$.

The present study can help those who want to learn how to write the editorials. Teachers of writing can use this research paper as a sample for teaching writing editorials. Students can be asked to identify the schematic structures of the specific editorials and classroom discussion can follow comparing with any editorials written in English in the world so that students can broaden their eyes, exposing the World English. For further study, it is suggested that the newspaper editorials are categorized into the sub-genre such as the environmental news, the political news, the health news and the comparison can be made between the findings. In addition, a larger scale of materials is suggested to have more reliable outcome.

\section{References}

Ansary, H., \& Babaii, E. (2005). The Generic Integrity of Newspaper Editorials: A Systemic Functional Perspective. RELC Journal,36(3), 271-295. Retrieved from https://doi.org/10.1177/0033688205060051

Ansary, H., \& Babaii, E. (2009). A cross-cultural analysis of English newspaper editorials: A systemic- functional view of text for contrastive rhetoric research. RELC Journal, 40 (2), 211-249.

Berger, P.L., \& Luckmann, T. (1966). The social ocn-struction of reality. New York: Anchor.

Bhatia, V. K. (2013). Analysing genre: Language use in professional settings. Routledge.

Eggins, S. (2004). Introduction to systemic functional linguistics. A\&C Black.

Fartousi, H., \& Dumanig, F. P. (2012). Rhetoric of Daily Editorials: A Review Study of Selected Rhetorical Analyses on Daily Editorials. Advances in Asian Social Sciences, 3 (2), 212251.

Halliday, M. A. K., \& Hasan, R. (1985). Dimensions of Discourse Analysis: Grammar. In The Handbook of Discourse Analysis.

Halliday, M. A. K., \& Hasan, R. (1989). Language, context, and text: Aspects of language in a social-semiotic perspective.

Literary Devices Editors. (2013). Background Information Retrieved on November 4, 2018, from https://literarydevices.net/background-information/

Martin, J, R. (1984). Language, register and genre. Children writing: reader, 1, 984.

Martin, J.R. (1985) Factual Writing: Exploring and Challenging Social Reality. Geelong, Vic.: Deakin University Press.

Martin, J.R., \& Rothery, J. (1986). What a functional approach to the writing task can show teachers about 'good writing'. Functional approaches to writing: Research perspectives, 241-265.

Olagunju, S. (2015). Generic structure potential of football matches in newspaper reporting. IOSR Journal of Humanities and Social Science, 38-50.

Pulido, D. H. (2011). A systemic functional analysis of Philippine English newspaper editorials. Tesol Journal, 4(1), 52-63.

Swales, J. (1990). Genre analysis: English in academic and research settings. Cambridge University Press. 
Exploring Generic Structure Potential of Selected Editorials in the Myanmar Times Newspaper, Ae Mon Kyaw, Xin Zhiying

Sunday, A. B., \& Faguleka, O. O. (2017). Generic Structure Potential Analysis of Feature Articles in Nigerian Newspapers. UJAH: Unizik Journal of Arts and Humanities, 18(1), 108-130.

Xin, B. (2012). The Generic Structure of the Editorials of People's Daily and Its Variability. Chinese Semiotic Studies, 6 (1), 15-38.

\section{APPENDIX}

The Myanmar Times. (2018, May 11). Ethnic conflicts and arms traders. Retrieved October 20, 2018 from The Myanmar Times website: https://www.mmtimes.com/news/ethnicconflicts-and-arms-traders.html.

The Myanmar Times. (2018, May 21). Ebola comes calling again, but have we learned 2014's lessons?. Retrived October 20, 2018 from The Myanmar Times website: https://www.mmtimes.com/news/ebola-comes-calling-again-have-we-learned2014s-lessons.html.

The Myanmar Times. (2018, May 24). The border between Bengal and Arakan. Retrieved October 30, 2018 from The Myanmar Times website: https://www.mmtimes.com/news/border-between-bengal-and-arakan.html.

The Myanmar Times. (2018, May 25). Moves in South China Sea a bigger threat than trade. Retrieved October 20, 2018 from The Myanmar Times website: https://www.mmtimes.com/news/moves-south-china-sea-bigger-threat-trade.html.

The Myanmar Times. (2018, May 29). Understanding the world's problem with tuberculosis. Retrieved October 30, 2018 from The Myanmar Times website: https://www.mmtimes.com/news/understanding-worlds-problem-tuberculosis.html.

The Myanmar Times. (2018, June 1). Age divide marks the digital age. Retrieved October 20, 2018 from The Myanmar Times website: https://www.mmtimes.com/news/agedivide-marks-digital-age.html.

The Myanmar Times. (2018, June 5). Hints of a formal end to Korean war. Retrieved October 20, 2018 from The Myanmar Times website: https://www.mmtimes.com/news/hintsformal-end-korean-war.html.

The Myanmar Times. (2018, July 6). Panglong conference, Panglong promises. Retrieved October 20, 2018 from The Myanmar Times website: https://www.mmtimes.com/news/panglong-conference-panglong-promises.html.

The Myanmar Times. (2018, June 8). China's attempt to change status quo in South China Sea unacceptable. Retrieved October 20, 2018 from The Myanmar Times website: https://www.mmtimes.com/news/chinas-attempt-change-status-quo-south-chinasea-unacceptable.html.

The Myanmar Times. (2018, June 8). The bride of Myanmar history. Retrieved October 20, 2018 from The Myanmar Times website: https://www.mmtimes.com/news/bridemyanmar-history.html.

The Myanmar Times. (2018, June 13). Canada has every right to be insulted over US tariffs. Retrieved October 20, 2018 from The Myanmar Times website: https://www.mmtimes.com/news/canada-has-every-right-be-insulted-over-ustariffs.html.

The Myanmar Times. (2018, June 14). Pope Francis opens his eyes on clerical sex abuse. Retrieved October 30, 2018 from The Myanmar Times website: https://www.mmtimes.com/news/pope-francis-opens-his-eyes-clerical-sexabuse.html. 
The Myanmar Times. (2018, June 18). Railway companies must do utmost to prevent attacks. Retrieved October 20, 2018 from The Myanmar Times website: https://www.mmtimes.com/news/railway-companies-must-do-utmost-preventattacks.html.

The Myanmar Times. (2018, June 22). Climate changes are here. Retrieved October 20, 2018 from The Myanmar Times website: https://www.mmtimes.com/news/climatechanges-are-here.html.

The Myanmar Times. (2018, June 27). Trump is playing a risky game of chicken with China. Retrieved October 20, 2018 from The Myanmar Times website: https://www.mmtimes.com/news/trump-playing-risky-game-chicken-china.html.

The Myanmar Times. (2018, July 27). Editorial: Hostile environment, protectionism hurt airlines and tourism. Retrieved October 20, 2018 from The Myanmar Times website: https://www.mmtimes.com/news/editorial-hostile-environment-protectionism-hurtairlines-and-tourism.html.

The Myanmar Times. (2018, June 29). A game that could be deadly. Retrieved October 20, 2018 from The Myanmar Times website: https://www.mmtimes.com/news/gamecould-be-deadly.html.

The Myanmar Times. (2018, July 13). Girl power is good for society. Retrieved October 20, 2018 from The Myanmar Times website: https://www.mmtimes.com/news/girlpower-good- society.html.

The Myanmar Times. (2018, July 20). Third Panglong: was it a success?. Retrieved October 30, 2018 from The Myanmar Times website: https://www.mmtimes.com/news/thirdpanglong-was-it-success.html.

The Myanmar Times. (2018, August 3) Citizens must be engaged in democracy. Retrieved October 20, 2018 from The Myanmar Times website: https://www.mmtimes.com/news/citizens-must-be-engaged-democracy.html.

The Myanmar Times. (2018, August 13). Myanmar snubs Rakhine report. Retrieved October 20, 2018 from The Myanmar Times website: https://www.mmtimes.com/news/myanmar-snubs-rakhine-report.html.

The Myanmar Times. (2018, August 17). Exchange rate fever. Retrieved October 20, 2018 from The Myanmar Times website: https://www.mmtimes.com/news/exchange-ratefever.html.

The Myanmar Times. (2018, Sep 14). Myanmar should not retreat into isolation. Retrieved October 20, 2018 from The Myanmar Times website: https://www.mmtimes.com/news/myanmar-should-not-retreat-isolation.html. 